\title{
Análise in silico do DNA genômico de três espécies do gênero Candida para verificação de ocorrência de microssatélites e observação de semelhanças interespecíficas
}

\author{
Analysis in silico of genomic DNA of three species of Candida for verification of \\ microssatellite occurrence and observation of interspecific similarities
}

Letícia Vieira Barbosa ${ }^{1}$, Iven Neylla Farias Vale Mendes ${ }^{1}$, Marcia Barros Alves ${ }^{2}$, Bruno Carvalho Campelo ${ }^{2}$, Karol Cristina Fonseca Moura ${ }^{2}$, Naiza Maria Castro Nogueira ${ }^{1}$, Cristina de Andrade Monteiro, ${ }^{1,2}$

Resumo: Nos últimos anos, estudos epidemiológicos apontam a contribuição relevante que fungos do gênero Candida, especialmente Candida albicans, vêm dando às infecções hospitalares e comunitárias, seguidas de altas taxas de morbidade e mortalidade, principalmente de lactentes e pacientes imunocomprometidos. Os protocolos comumente conhecidos para análise e identificação das espécies são muito caros e demorados e, por isso, estudos in silico dos microssatélites ou SSR (Simple Sequence Repeat) se tornaram importantes marcadores moleculares proporcionando à engenharia genética uma estratégia para ligar variações do genótipo às variações fenotípicas sem a utilização de métodos caros e demorados de análise. O presente trabalho avaliou a presença de SSR em sequências de DNA de diferentes espécies de Candida depositadas no GenBank a fim de detectar possíveis diferenças entre elas através de programas específicos. Em Candida albicans foram identificados maior número de SSR além de maior variedade de motivos (repetições). Foi detectado um número reduzido de microssatélites em $C$. tropicalis (cinco) e nenhum foi encontrado em C. parapsilosis. A utilização de SSR como ferramenta de identificação de Candida foi considerada satisfatória, pois revelou importantes diferenças entre as espécies analisadas quanto a presença e os tipos de SSR.

Palavras-chave: Candida, microssatélite, SSR, Candidíase

\begin{abstract}
Hospital infections caused by fungi have been established as a growing public health problem in many countries. In recent years, epidemiological studies have pointed out the significant contribution that fungi of the genus Candida, especially Candida albicans, are giving to the hospital and community infections, followed by high rates of morbidity and mortality, especially in infants and immunocompromised patients. Commonly known protocols for species analysis and identification are very expensive and time-consuming and, therefore, in silico microsatellite studies or SSR (Simple Sequence Repeat) analysis have become important molecular markers providing genetic engineering a strategy to link genotype variations to phenotypic variations without the use of expensive and timeconsuming methods of analysis. The present work evaluated the presence of SSR in DNA sequences from different Candida species deposited in GenBank in order to detect possible differences among them through specific programs. In Candida albicans, a greater number of SSRs was identified, in addition to a greater variety of motifs (repetitions). A small number of microsatellites was detected in C. tropicalis (five) and none was found in C. parapsilosis. The use of SSR as a tool to identify Candida spp. was considered satisfactory, as it revealed important differences between the species analyzed for the presence and types of SSR.
\end{abstract}

Keywords: Candida, microssatellites, SSR, Candidiasis

1 - Docentes - Instituto Federal do Maranhão

2 - Docentes - Universidade CEUMA

Rev. Investig, Bioméd. São Luís, 9:6-16, 2017 
Introdução

As infecções hospitalares causadas por fungos tem representado problema crescente de saúde pública em muitos países. Estudos epidemiológicos realizados no Brasil apontam Candida como um dos principais agentes de infecções nosocomiais ${ }^{1}$ e se mostrou presente em muitos casos de infecções sistêmicas podendo ser classificada como a sétima mais prevalente ${ }^{2}$. Altas taxas de morbidade e mortalidade, principalmente de lactentes e pacientes imunocomprometidos ${ }^{3}$ foram observadas e, portanto, estes casos constituem um grave problema de saúde pública.

Vários processos patológicos, fisiológicos ou traumáticos podem facilitar a colonização e posterior infecção do hospedeiro por Candida spp. Dentre estes, os mais comuns são imunossupressão por várias causas, neutropenia, desnutrição e quimioterapia anti neoplásica ${ }^{4}$.

Espécies do gênero Candida apresentam variações na sua composição genômica que podem ser determinadas por procedimentos de análise genômica ${ }^{5}$. Estes procedimentos são úteis quando se quer determinar a identidade do isolado presente no ambiente hospitalar ou do que tenha vindo de pacientes internados, e assim associálos aos processos infecciosos ${ }^{6}$.

Várias metodologias têm sido utilizadas para a tipagem de $C$. albicans ${ }^{7,8,9,10}$. Contudo, a maior parte delas depende de processos demorados e de alto custo, se executado em laboratórios por meio de protocolos comumente conhecidos.

Nos últimos anos, o projeto genoma e o surgimento de novas metodologias de sequenciamento propiciaram a redução dos custos e aumento expressivo do número de sequências depositadas no Genbank/NCBI (National Center for Biotechnology Information Search Database), que é o mais conhecido banco de dados que disponibiliza,

gratuitamente, sequências e ferramentas para sua análise. Este banco foi criado, inicialmente, pelo Centro Nacional para Informação Biotecnológica (NCBI) com o objetivo de abrigar sequências submetidas diretamente por autores de publicações científicas. Entretanto, não só autores, como também centros de pesquisa passaram a depositar regularmente seus dados ${ }^{11}$.

$A$ análise de sequências e a utilização de marcadores genéticos permitem ao pesquisador classificar os isolados e assim verificar semelhanças genéticas entre eles. Um dos marcadores que podem ser utilizados são os microssatélites ou SSRs (Simple sequence repeat). Essas sequências são formadas pela repetição em série de nucleotídeos dispostos em arranjos contendo entre um e seis pares de bases ${ }^{12}$. Estes locos podem ser encontrados em sequências gênicas (CDS - CoDing Segment), 5'-UTR - Untranslated region 5', 3'-UTR - Untranslated region 3' e íntrons) e intergênicas, podendo conduzir a um ganho ou perda de função dos genes. Variações nas regiões SSR se originam principalmente a partir de erros durante 0 processo de replicação, frequentemente relacionados a erros da DNA polimerase, podendo gerar inserção ou deleção de pares de bases, resultando, respectivamente, em regiões maiores ou menores. Avaliações de SSR no genoma humano têm demonstrado que muitas doenças são causadas por mutações nestas sequências revelando a importância de estudar essas regiões. Esta classe de marcadores é poderosa 
em diversas aplicações da genética e melhoramento, devido a sua reprodutibilidade, natureza multialélica, característica co-dominante e abundância genômica, proporcionando aos geneticistas e melhoristas uma estratégia para ligar variações do genótipo às variações fenotípicas ${ }^{13}$.

$$
\text { Muitos microssatélites }
$$

encontram-se em partes nãocodificantes do genoma e, portanto, são biologicamente silenciosos. Isto permite que acumulem mutações sem obstáculos ao longo das gerações e dá origem à variabilidade que pode ser utilizado para fins de tipagem (fingerprint) de DNA e identificação individual. Outros microssatélites estão localizados em regiões de flanqueamento ou regiões intrônicas dos genes ${ }^{14}$. É possível destacar que podem ser feitos uma grande variedade de trabalhos envolvendo microssatélites, principalmente, por três características presentes nesse marcador: (1) a elevada abundância com ampla distribuição pelo genoma; (2) a neutralidade e (3) o alto polimorfismo.

Os microssatélites permitem analisar com eficiência a estrutura genética de populações por apresentarem um maior conteúdo informativo por loco gênico do que outros marcadores moleculares. Permite, inclusive, observar diferenças genéticas em populações separadas por poucos quilômetros, em uma escala microgeográfica ${ }^{15}$. Assim, indicam os microssatélites, devido ao alto polimorfismo, como a metodologia mais eficiente para separar subespécies.

O presente trabalho teve como objetivo verificar a ocorrência in silico de microssatélites em DNA de três espécies de micro-organismos do gênero Candida.

\section{Materiais e Métodos}

A partir do website do NCBI (www.ncbi.nih.gov), foi realizada pesquisa para o genoma das espécies C. albicans, C. tropicalis e C. parapsilosis. Para a seleção das sequências utilizou-se a opção "EST" (expressed sequence tag) que funciona como filtro da pesquisa.

As sequências de DNA referentes ao genoma das três espécies foram localizadas e em seguida depositadas em arquivos no padrão FASTA para posterior análise em programa adequado.

Após depósito, o alinhamento das sequências genômicas foi realizado pelo programa computacional Bioedit, com acesso disponível e gratuito para download, após procura em sites de buscas. Os alinhamentos das regiões de microssatélites foram executados com o objetivo de posterior importação para - SSR Locator e início da análise proposta $^{16}$. Após 0 processo de alinhamento, os arquivos individuais contendo as sequências alinhadas são importados para o SSRLocator, programa computacional especifico para triagem e consequente detecção de SSR (Figura 1). 


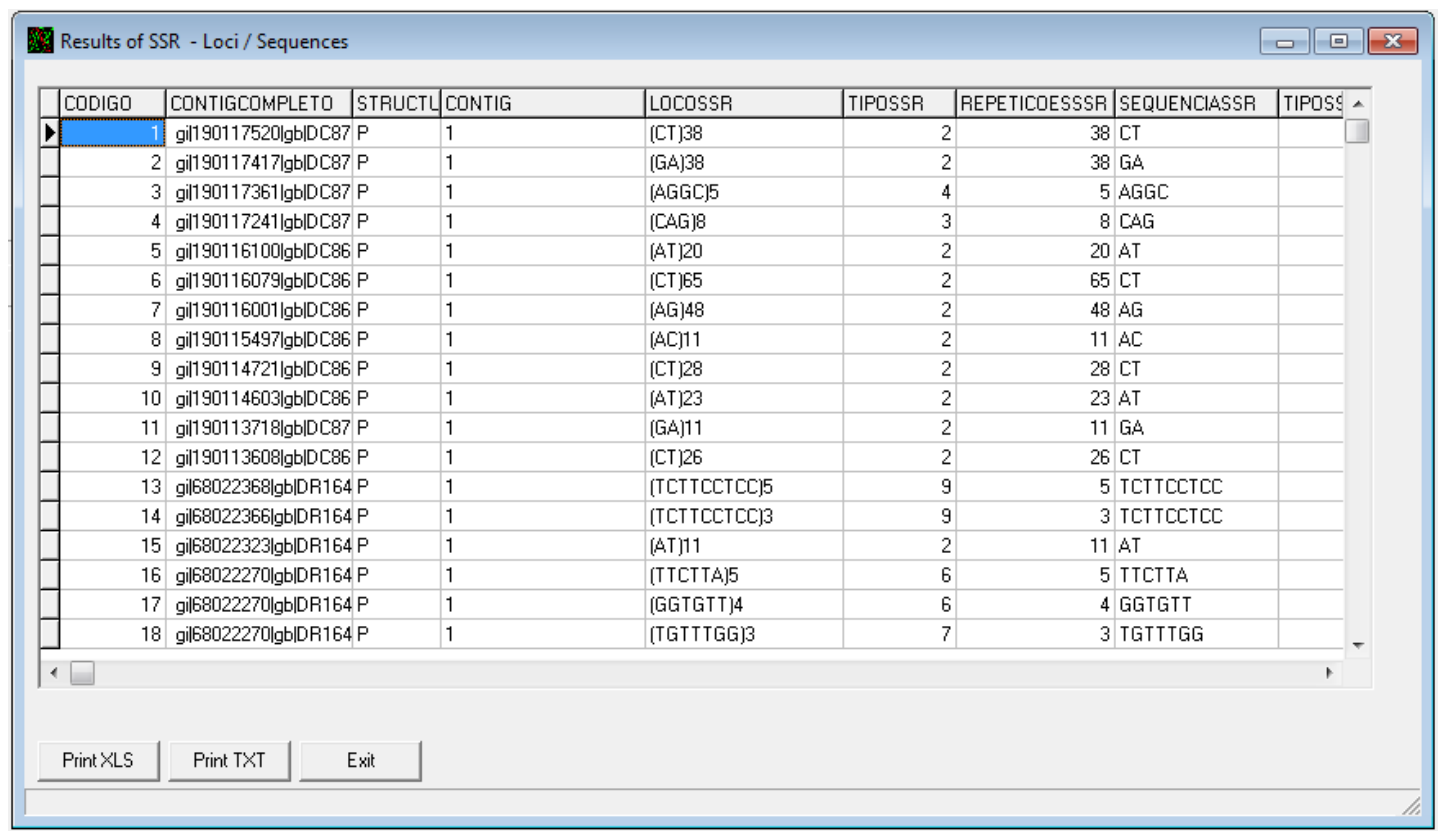

A configuração para os motivos (arranjo dos microssatélites) a serem localizados compreenderam arranjos formados com repetições mínimas de dez pares de base para dímeros $(2 \mathrm{x}$ $10)$, sete para trímeros, $(3 \times 7)$, cinco para tetrâmeros $(4 \times 5)$ e pentâmeros (5x5), quatro para hexâmeros $(6 \times 4)$ Ao término de cada entrada, o aplicativo gera arquivos descritivos em formato de texto puro; um pipeline desenvolvido em linguagem de programação $(\mathrm{PERL})^{16}$.

As sequências foram estudadas, analisadas e separadas em arranjos de microssatélites nãoredundantes em classes. Para a verificação de identidade entre sequências genômicas também foi usado o BioEdite apenas sequências não-redundantes foram selecionadas, ou seja, aquelas com similaridade(identidade) acima de $90 \%$ foram descartadas.

Após a verificação da identidade das sequências no programa BioEdit, a detecção de microssatélites foi executada então pelo SSRLocator.

Um arquivo, a partir das sequências, foi gerado para análise por meio do diretório Creat File.

\section{Resultados}

A análise computacional revelou além das sequências de EST de Candida albicans que apresentam contigs com ocorrência de microssatélites (Figura 2), os tipos de microssatélites encontrados nas sequências de EST em seus respectivos loci (Figura 3). 


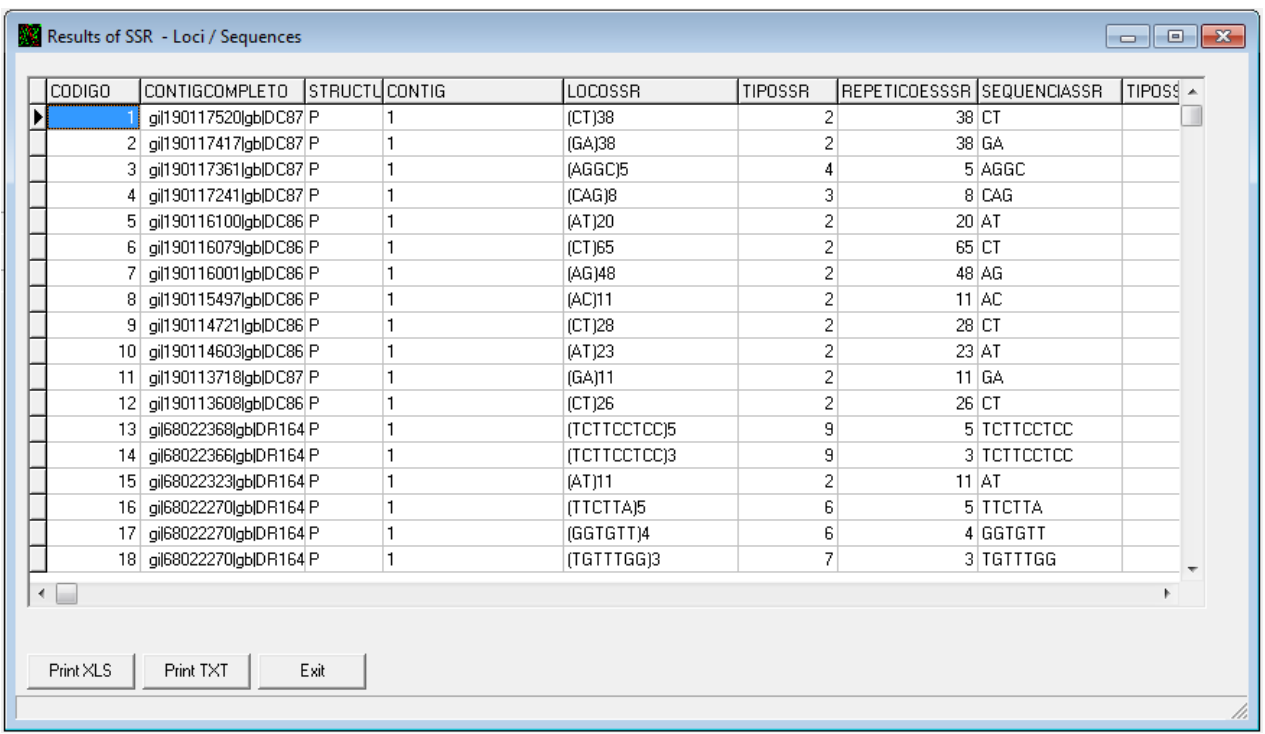

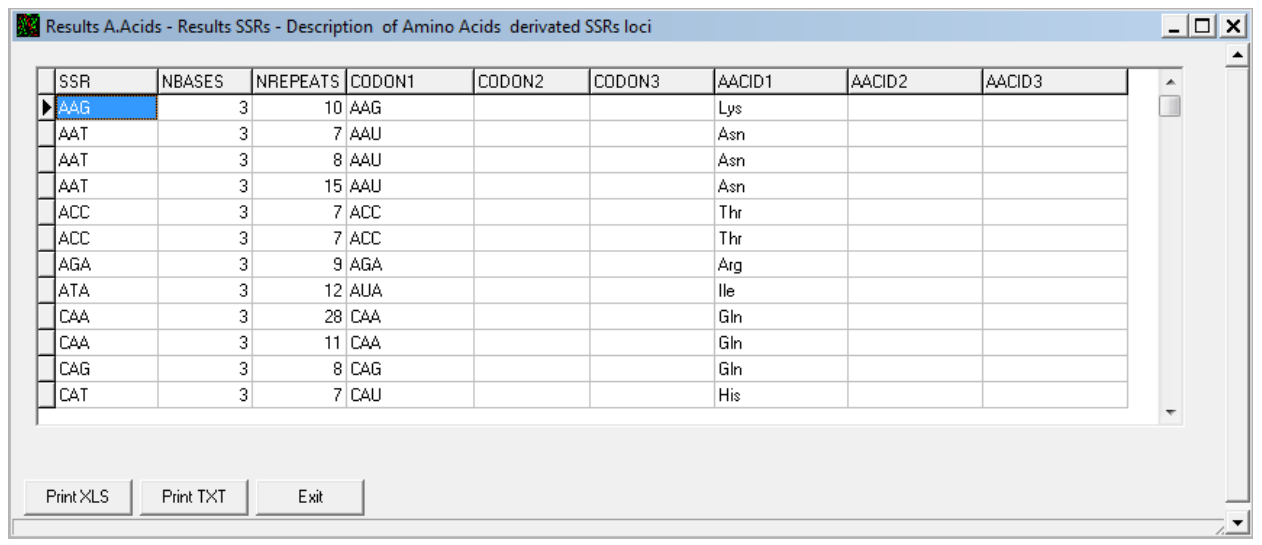

Além disso, foi possível observar a ocorrência de microssatélites que geram códons e consequentemente aminoácidos repetidos nesta espécie conforme (Figura 4).

\begin{tabular}{|c|c|c|c|c|c|c|c|c|c|}
\hline \multicolumn{7}{|c|}{ Results A.Acids - Results SSRs - Description of Amino Acids derivated SSRs loci } & & \multicolumn{2}{|c|}{ - $\square x$} \\
\hline SSR & NBASES & |NREPEATS $\mid$ CODON1 & CODON2 & CODON3 & $\mathrm{AACID} 1$ & $\mathrm{AACID2}$ & $\mathrm{AACID} 3$ & 1 & \\
\hline$\sqrt{A A G}$ & & $10 \mathrm{AAG}$ & & & Lys & & & $\square$ & \\
\hline AAT & & $7 \mathrm{AAU}$ & & & Asn & & & & \\
\hline $\mathrm{AAT}$ & & $8 \mathrm{AAU}$ & & & Asn & & & & \\
\hline AAT & & $15 \mathrm{AAU}$ & & & Asn & & & & \\
\hline$A C C$ & & $7 \mathrm{ACC}$ & & & Thr & & & & \\
\hline $\mathrm{ACC}$ & & $7 \mathrm{ACC}$ & & & Thr & & & & \\
\hline $\mathrm{AGA}$ & & $9 \mathrm{AGA}$ & & & Arg & & & & \\
\hline ATA & & 12 AUA & & & Ile & & & & \\
\hline CaA & & $28 \operatorname{CAA} A$ & & & Gin & & & & \\
\hline CAA & & 11 CAA & & & Gin & & & & \\
\hline CAG & & $8 \mathrm{CAG}$ & & & Gin & & & & \\
\hline САТ & & 7 CAU & & & His & & & & \\
\hline Print XLS & Print $T \times T$ & Exit & & & & & & & - \\
\hline
\end{tabular}


Foram encontrados números variáveis de microssatélites em $C$. albicans (Figura 5).

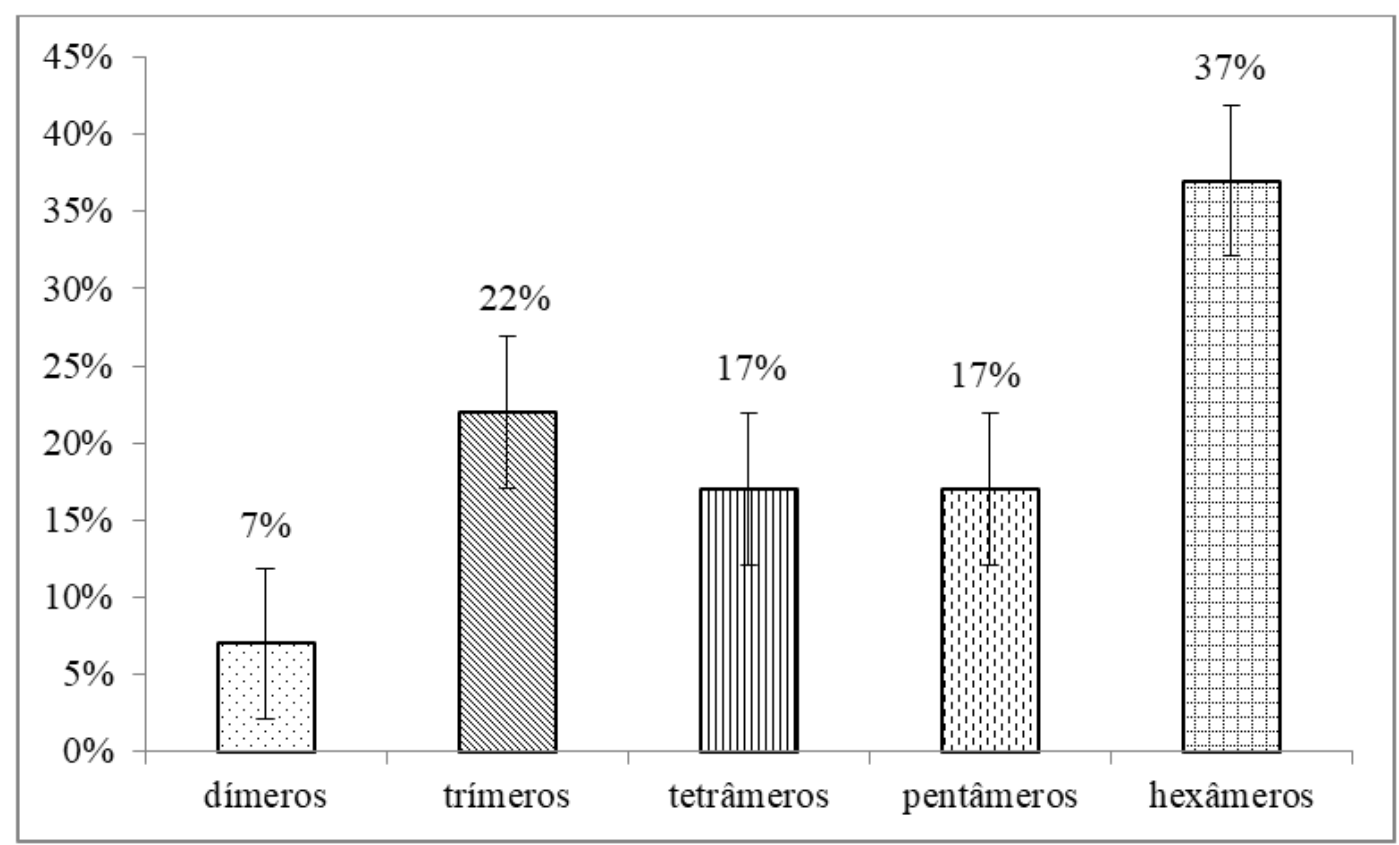

As análises apontam rica variedade de tipos e repetições de microssatélites sendo detectada uma frequência maior de hexâmetros (37\%) seguido de trímeros $(22 \%)$, tetrâmeros $(17 \%)$, pentâmeros $(17 \%)$ e dímeros em menor frequência $(7 \%)$.

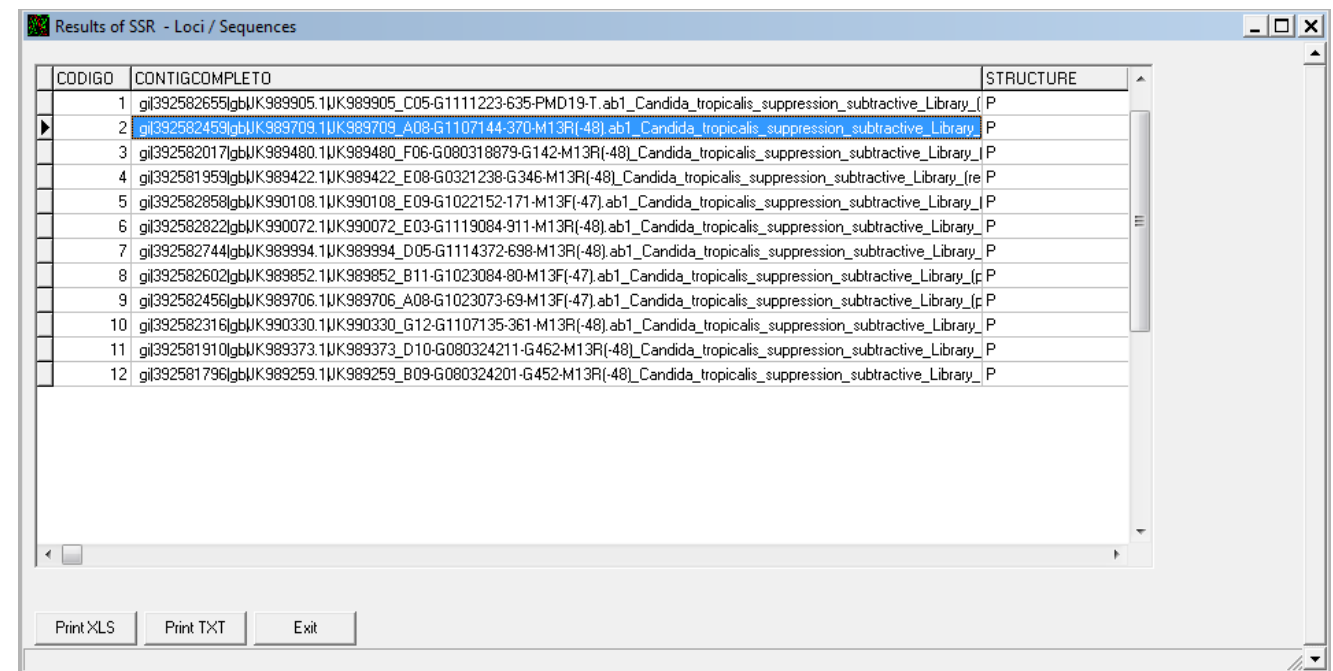

A figura 6 mostra a ocorrência de 12 contigs de $C$. tropicalis que apresentam sequências de microssatélites. A mesma configuração de arranjos de microssatélites foi aplicada na triagem das três espécies, entretanto não foi observada a ocorrência de tetrâmeros, pentâmeros e hexâmetros em $C$. tropicalis na sequência EST estudada (Tabela 1). 


\begin{tabular}{ccc}
\hline Tipo SSR & Sequencia SSR & Repetições SSR \\
\hline 3 & CA & 11 \\
3 & TCA & 9 \\
3 & TTC & 8 \\
3 & ACT & 8 \\
2 & AAT & 7 \\
\hline
\end{tabular}

Assim como em C. albicans, também foram avaliados os loci de SSR para $C$. tropicalis dentro de regiões codificantes e os aminoácidos resultantes (Figura 7).

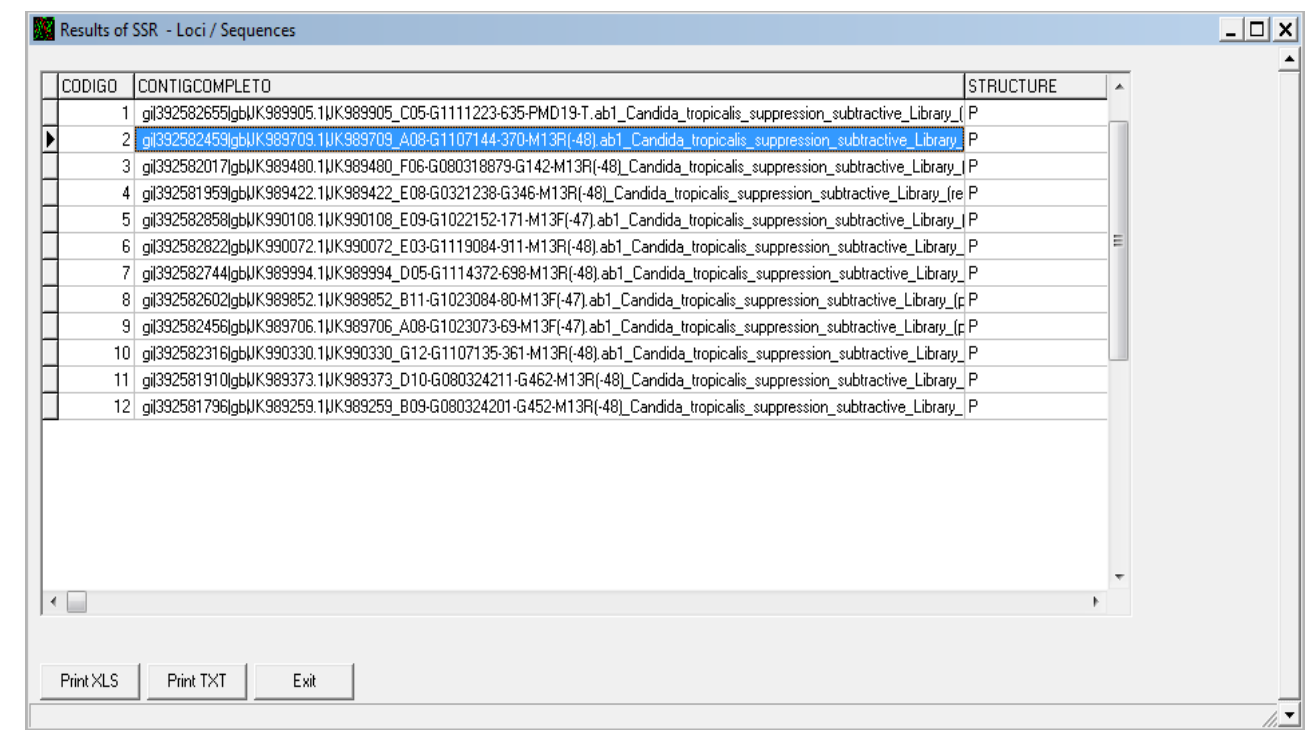

Para C. parapsilosis os resultados foram divergentes em comparação com as outras espécies analisadas. A frequência de regiões de microssatélites nessa espécie era muito baixa, entretanto, o programa não detectou nenhum SSR na sequência EST de C. parapsilosis. 


\section{Discussão}

A análise de microssatélites já é amplamente utilizada não somente como formas de identificação intra ${ }^{17,18}$ e interespecífica ${ }^{19}$, mas também para determinação de perfil de sensibilidade a antifúngicos ${ }^{20}$ e controle de infecção hospitalar ${ }^{21}$.

Apesar de esperada uma probabilidade de ocorrência de microssatélites iguais entre as espécies, por serem do mesmo gênero, os resultados desta pesquisa apontam para uma grande quantidade de diferenças entre as mesmas, com poucas similaridades.

Houve poucas semelhanças nos tipos de arranjos de microssatélites que ocorrem em $C$. tropicalis e $C$. albicans e muita diferença na concentração de bases nitrogenadas (adenina, citosina, guanina e timina, respectivamente A, C, G e T) observadas nos microssatélites.

Em C. albicans há grande variedade no número de repetições para os dímeros GA e CT. O mesmo não é observado em $C$. tropicalis para nenhum tipo de microssatélite. $A$ primeira espécie detém, também, maior variedade nos tipos de SSR, sendo observada a ocorrência de dímeros, trímeros, tetrâmeros, pentâmeros e hexâmeros.

Não houve ocorrência de um único microssatélite que fosse ordinário em ambas. Nem mesmo dímeros que são conhecidos como comuns na maioria das espécies. Também não foi observada presença de tetrâmeros, pentâmeros e hexâmeros nas sequências de $C$. tropicalis.

Mesmo com poucas semelhanças entre os microssatélites nas sequências analisadas destas duas espécies, há o ponto positivo da possibilidade de utilização de tais SSR apresentados como marcadores moleculares para diferenciação segura entre amostras, visto que visualmente são muito parecidas.

Traçando-se um comparativo entre $C$. albicans e $C$. tropicalis, notase alta concentração das bases nitrogenadas citosina e guanina para a primeira espécie e concentração de adenina para a segunda.

Estudos envolvendo microssatélites realizados com $C$. albicans revelaram uma distribuição genotípica única de $C$. albicans associada à vulvovaginite por Candida $^{22}$ demonstrando que a aplicabilidade dos estudos de microssatélites pode ir além da identificação e promover ferramentas para análise de isolados potencialmente patogênicos.

Microssatélites em $C$. tropicalis também já foram estudados ${ }^{23}$ e foi possível utilizar esse marcador para identificação de linhagens dessa espécie.

Embora o estudo não tenha revelado presença de microssatélites em $C$. parapsilosis esse tipo de marcador vem sendo utilizado com sucesso para distinção entre isolados de $C$. parapilosis como $C$. ortopsilosis, $C$. metapsilosis e $C$. parapsolosis stricto sensu $^{24}$. Os novos microssatélites são uma valiosa ferramenta para a diferenciação de C. parapsilosis stricto sensu eimportante na epidemiologia para responder a questões de tensão e determinar vias de transmissão.

A cada dia novas sequencias de DNA genômico estão sendo adicionadas aos bancos de dados 0 que viabiliza ainda mais os estudos de análise in silico diminuindo gastos com materiais de consumo, equipamentos e infra-estrutura para as análises convencionais. Além disso, é uma ferramenta que pode ser facilmente manipulada e demandando curto tempo de formação de recursos humanos, com necessidades apenas 
de conhecimento básico em genética, biologia molecular e bioinformática.

\section{Conclusão}

Os microssatélites estão amplamente distribuídos no genoma de $C$. albicans e C. tropicalis. Ainda que venham de um mesmo gênero, estas espécies provaram que realmente não possuem grandes semelhantes a nível molecular em relação às áreas analisadas, muito embora sejam extremamente parecidas em termos fenotípicos quando analisadas morfologicamente. Desta forma, os marcadores identificados podem ser testados experimentalmente por meio de técnicas moleculares para identificação específica das espécies estudadas. Nas condições testadas, não houve identificação de microssatélites em $C$. parapsilosis entretanto, o aumento constante de genomas inseridos em bases de dados poderá revelar marcadores nesta espécie em estudos posteriores.

Devido à semelhança fenotípica e para evitar que haja dúvidas ou erros na diferenciação bioquímica/morfológica entre isolados, sugere-se fazer uma análise dos mesmos a nível molecular usando marcadores microssatélites. As regiões de microssatélites identificadas e descritas neste trabalho são potenciais candidatos que podem ser empregados em testes de biologia molecular como marcadores moleculares específicos para identificação precisa dos isolados das espécies aqui avaliadas.

\section{Referências}

1. Lockhart SR, Etienne KA, Vallabhaneni S, Farooqi J, Chowdhary A, Govender NP, Calvo B, Cuomo CA, Desjardins CA, Berkow EL, Castanheira M, Magobo RE, Jabeen
$\mathrm{K}$, Asghar RJ, Meis JF, Jackson B,

Chiller T, Litvintseva AP.

Simultaneous emergence of multidrug-resistant Candida auris on 3 continents confirmed by wholegenome sequencing and epidemiological analyses. Clinical Infectious Diseases. 2016; 64(2):134140.

2. Doi, AM, Pignatari ACC, Edmond MB, Marra AR, Camargo LFA, Siqueira RA et al. Epidemiology and microbiologic characterization of nosocomial candidemia from a Brazilian national surveillance program. PloS one, 2016,11(1)1-9

3. Chakravarthi S, Haleagrahara N. A comprehensive review of the occurrence and management of systemic Candidiasis as an opportunistic infection. Microbiology Journal.2011,1:1-7.

4. Barot N, Vegad M, Soni S; Sharma K, Shah K. Candida Infection in Intensive Care Unit Patients at Tertiary Care Hospital. Healthline, Journal of Indian Association of Preventive and Social Medicine, 2015,6(1)53-56.

5. Trick WE, Fridkin SK, Edwards JR, Hajjeh RA, Gaynes RP. Secular trend of hospital-acquired candidemia among intensive care unit patients in the United States during 1989-1999 Clinical Infectious

Diseases,2002,35(5):627-630

6. Taylor JS, Durkin JM, Brenden F. The death of a microsatellite: a phylogenetic perspective on microsatellite interruptions. Molecular Biology and Evolution, 1999 16(4):567-572.

7. Lacroix C, Gicquel A, Sendid B, Meyer J, Accoceberry I, François N, Morio F, Desoubeaux G, Chandenier J, Kauffmann-Lacroix C, Hennequin C, Guitard J, Nassif X, M.-E. Bougnoux. Evaluation of two matrix-assisted laser desorption ionization-time of flight mass spectrometry (MALDI-TOF MS) 
systems for the identification of Candida species. Clinical Microbiology and Infection, 2014,20(2), 153-158

8. Foongladda S, Mongkol N, Petlum P, Chayakulkeeree M. Multi-probe realtime PCR identification of four common Candida species in blood culture broth. Mycopathologia, 2014, 177(5-6), 251-261.

9. Gómez-Molero E, Dekker HL, de Boer $A D$, de Groot PW. Identification of secreted Candida proteins using mass spectrometry. Candida Species: Methods and Protocols,2016, 79-94.

10. Stefaniuk E, Baraniak A, Fortuna M, Hryniewicz W. Usefulness of CHROMagar Candida Medium, Biochemical Methods--API ID32C and VITEK 2 Compact and Two MALDITOF MS Systems for Candida spp. Identification. Pol Microbiol,2016,65(1), 111-14.

11. Tateno $\mathrm{Y}$, Imanishi $\mathrm{T}$, Miyazaki $\mathrm{S}$, Fukani-Kobayashi K, Saitou N, Sugawara H, Gajobori T. DNA databank of Japan (DDBJ) for genome scale research in life science. Nucleic Acids Research,2002,v.30, 27-30.

12. Morgante M, Olivieri A. PCR-amplified microsatellites as markers in plant genetics. The plant journal, 1993,3(1),175-182.

13. Varshney RK, Graner A, Sorrells, ME. Genic microsatellite markers in plants: features and applications. TRENDS in Biotechnology, 2005, 23(1), 48-55.

14. Richard GF, Kerrest A, Dujon B. Comparative genomics and molecular dynamics of DNA repeats in eukaryotes. Microbiology and Molecular Biology Reviews, 2008,72(4), 686-727.

15. Costa-Ribeiro MCVD, Lourenço-deOliveira R, Failloux AB. Higher genetic variation estimated by microsatellites compared to isoenzyme markers in
Aedes aegypti from Rio de Janeiro. Memórias do Instituto Oswaldo Cruz, 2006, 101(8), 917-921.

16. Da Maia LC, Palmieri DA, De Souza, VQ, Kopp MM, de Carvalho FIF, Costa de Oliveira A. SSR locator: tool for simple sequence repeat discovery integrated with primer design and PCR simulation. International Journal of Plant Genomics, 2008, 1-9.

17. Fan $X$, Xiao $M$, Liu $P$, Chen, $S$, Kong F, Wang $\mathrm{H}$, Zhang L, Hou X, Xu, YC. Novel polymorphic multilocus microsatellite markers to distinguish Candida tropicalis isolates. PloS one, 2016, 11(11)

18. Chillemi V, Passo $\mathrm{CL}$, van Diepeningen $A D$, Rharmitt $S$, Delfino D, Cascio A, Nnadi NE, Cilo BD, Sampaio $\mathrm{P}$, Tietz $\mathrm{H}-\mathrm{J}$, Pemán J, Criseo G, Romeo O, Scordino F. Multilocus microsatellite analysis of European and African Candida glabrata isolates. European Journal of Clinical Microbiology \& Infectious Diseases, 2016, 35(6), 885-892.

19. Garcia-Hermoso D, Desnos-Ollivier M, Bretagne S. Typing Candida species using microsatellite length polymorphism and multilocus sequence typing. Candida Species: Methods and Protocols, 2016,199214.

20. Ngouana TK, Drakulovski $P$, Krasteva D, Toghueo RK, Kouanfack C, Reynes J, Delaporte E, Boyom FF, Mallié M, Bertout, S. Genetic diversity of the Hwp1 gene and HIS3, EF3, CDC3 microsatellites and antifungal susceptibility profiles of Candida albicans isolates from Yaounde HIVinfected patients. Medical mycology, 2016.

21. Sabino R, Sampaio $P$, Veríssimo $C$, Pais C. Genotipagem de Candida parapsilosis com marcadores de DNA microssatélite: uma ferramenta para o estudo e controlo das infeções 
hospitalares. Boletim Epidemiológico Observações, 2014,3, 30-33.

22. Li C, Wang L, Tong $\mathrm{H}, \mathrm{Ge} \mathrm{Y}$, Mei $\mathrm{H}$, Chen L, Lv G, Liu W. Microsatellite analysis of genotype distribution patterns of Candida albicans. Archives of gynecology and obstetrics, 2016, 294(2), 291-297.

23. Wu Y, Zhou HJ, Che J, Li WG, Bian FN, Yu SB, Zhang LJ, Lu J. Multilocus microsatellite markers for molecular typing of Candida tropicalis isolates. BMC microbiology, 2014,14(1), 245.

24. Sabino $R$, Sampaio $P$, Rosado $L$, Stevens DA, Clemons KV, Pais C. New polymorphic microsatellite markers able to distinguish among Candida parapsilosis sensu stricto isolates. Journal of clinical microbiology, 2010, 48(5), 1677-1682. 